P176 (continued)

Outcome Measures and Analysis: Free lists were analyzed for total number and most commonly listed items.

Results: Exploratory analysis revealed a wide range for total numbers of foods and drinks listed by each food group and individual respondents. For children, 2-12 fruits, 3-13 vegetables, and 3-13 drinks were listed, whereas parents listed 1-19 fruits, 6-24 vegetables, and 4-13 drinks, respectively. Apples, bananas, oranges, fruit juices, and water were listed by over half of both groups, and while many vegetables were listed by over half of parents, only carrots were listed by more than half the children.

Conclusions and Implications: These data include a wider variety of foods and beverages than anticipated based on formative work, and will help inform a parent messaging intervention targeted at improving eating behaviors among middle-school children by providing insight into potential foods and drinks, as well as recipes, to recommend to parents.

Funding: USDA.

\section{P177 Fuel for Fun Impact Study Affirms Positive Effect on Fruit and Vegetable Preference and Approach to Cooking in School Age Youth} Barbara Lohse, PhD, RD, LDN, lohse.ba@gmail.com, Pennsylvania State University, 205 Chandlee Lab University, Park, PA 16802; S. Smith, MS, RD, Colorado State University; L. Cunningham-Sabo, PhD, RD

Objective: To examine impact of Fuel for Fun (FFF), a school-based experiential cooking intervention on selfefficacy (SE) and attitude (AT) toward cooking and on fruit and vegetable preference (FVP).

Design, Setting and Participants: Controlled study of students ( $\mathrm{n}=767 ; 75 \%$ white, $51 \%$ boys, mean BMI z-score $.24 \pm 1.1$ ) in 234 th or $4 / 5$ th grade classrooms, in 8 schools over 2 years with Cohort $1(\mathrm{C} 1 ; \mathrm{n}=415)$ as control and Cohort $2(\mathrm{C} 2 ; \mathrm{n}=352)$ participating in FFF over the academic year. C1 and C2 were surveyed at the start (T1) and end of the school year (T2) and start of the next school year (T3). Study personnel administered a tested, reliable survey set in classrooms.

Outcome Measures and Analysis: FVP (18 items); cooking SE (8 items); AT toward cooking (6 items), cooking experience (CE); GLM using repeated measures.

Results: Surveys were completed at 3 times by 73\%; T1 completer scores did not differ from attriters. T1 to T3 SE, AT, FVP scores did not differ by gender. Those with CE $(\mathrm{n}=532)$ scored significantly higher on all surveys. Change over time was significant for all measures with $>$ increases in $\mathrm{C} 2$ for $\mathrm{SE}(\mathrm{P}=0.001)$, AT $(\mathrm{P}=0.003)$; this pattern continued when controlling for $\mathrm{CE}$ for SE and AT. FVP tended $(\mathrm{P}=0.09)$ to increase for $\mathrm{C} 2$ when controlling for $\mathrm{CE}$ and school district. T1 to T2 changes remained improved at T3.

Conclusions and Implications: Controlled study over 12 months revealed FFF increased FVP and SE and AT toward cooking. Evidence-base of this program is reaffirmed in a mostly white sample and supports use in school-based nutrition education.

Funding: NIFA.

\section{P178 Assessment of Fruit and Vegetable (FV) Intakes and Dietary Patterns of Preadolescents Ages 8 to 14 Years}

Weiwen Chai,PhD, wchai2@unl.edu, University of Nebraska-Lincoln, 104B Leverton Hall, Lincoln, NE 68583; M. Nepper, MS, RD

Objective: To assess fruit and vegetable intakes and dietary patterns of preadolescents ages 8 to 14 years.

Design, Setting and Participants: A total of 327 preadolescents (age: $11.0 \pm 1.3$ years) in a Midwestern metro area participated in the study. Each participant completed a 41 item food frequency questionnaire and an additional demographic survey in their regular classroom settings.

Outcome Measures and Analysis: Participants were clustered into three groups defined by variables related to fruit and vegetable intakes using cluster analysis. Mean dietary intakes of total fruit, vegetables, protein, whole grains, milk, and sweetened snacks (e.g., cookies, donuts) were compared between the clusters using ANOVA.

Results: Overall, large portions of preadolescents reported that they consumed tomato (91.1\%), lettuce salad $(78.5 \%)$, green bean or pea $(86.7 \%)$, or other vegetables $(52.5 \%)$ less than three days per week. $26.0 \%, 42.5 \%$, and $27.5 \%$ of the participants were classified into low (FV score: $8.3 \pm 3.9$ ), medium (FV: $14.2 \pm 4.5$ ), and high (FV: $20.7 \pm 5.6) \mathrm{FV}$ groups, respectively. High FV group had higher protein, whole grain, and lower sweetened snack intakes compared to low FV group (Ps $<0.05$ ). No differences in milk consumption between the clusters were observed $(\mathrm{P}=0.28)$.

Conclusions and Implications: Results indicate that dietary fruit and vegetable intakes of preadolescents in our study were positively associated with total protein and whole grain and inversely associated with sweetened snack intakes. Our findings that many preadolescents had low vegetable consumptions, warranting strategic interventions to improve healthy-eating.

Funding: University of Nebraska-Lincoln Research Council Faculty Seed Grant.

\section{P179 iCook 4-H: Report of the Accelerometer Derived Physical Activity in 9-10 Year Old Children From Baseline to Post}

Chase Merfeld, BS, chase.merfeld@sdstate.edu, South Dakota State University, 701 Priarie View Drive, Apartment \#2, Brookings, SD 57006; K. Kattelmann, PhD, RDN, LN, FAND; J. Meendering, PhD, ATC, HFS; L. FranzenCastle, PhD, RD, MS, University of Nebraska-Lincoln; M. Olfert, DrPH, MS, RDN, LDN, West Virginia University; S. E. Colby, $P h D, R D$, University of Tennessee;

A. White, $P h D, R D$, University of Maine 